\title{
Sky view factor as predictor of solar availability on building façades
}

\author{
Christina Chatzipoulka ${ }^{\mathrm{a}, \mathrm{b}, *}$, Raphaël Compagnon ${ }^{\mathrm{b}}$, Jérôme Kaempf ${ }^{\mathrm{b}}$, Marialena Nikolopoulou ${ }^{\mathrm{a}}$ \\ ${ }^{a}$ Kent School of Architecture, University of Kent, Marlowe Building, CT2 7NR Canterbury, United Kingdom \\ ${ }^{\mathbf{b}}$ Haute Ecole d'Ingénierie et d'Architecture de Fribourg, Bd Pérolles 80, 1700 Fribourg, Switzerland
}

\section{A R T I C L E I N F O}

\section{Keywords:}

Solar potential

Solar indicator

Sky view factor

Urban façades

Orientation

\begin{abstract}
A B S T R A C T
Solar availability on urban façades varies significantly, affected by obstructions by nearby buildings as well as orientation. A convenient way to evaluate their solar energy potential is deemed to facilitate the task of architects in increasing the use of photovoltaic systems and, thus solar energy generation in the urban environment. This study explores to what extent the sky view factor (SVF), a measure of the openness of a point to the sky, can be employed for evaluating solar irradiation of façades in complex urban scenes. For this purpose, extensive statistical analysis was performed testing the correlation of SVF with solar irradiances for 30 orientations, considering three European climates (i.e. Athens, London and Helsinki), and three periods (i.e. year, January and July). Special emphasis is put on global irradiance, which expresses the sum of three solar components, i.e. direct, diffuse and reflected. The study uses 24 urban forms - of $500 \times 500 \mathrm{~m}$ area - in London for which SVF and solar irradiance simulations were performed for nine sky models (three locations by three periods). The results reveal a strong linear relationship $\left(\mathrm{R}^{2}>0.8\right)$ between SVF and annual global irradiance in all orientations, at all three locations. In fact, as SVF was found to correlate well with both major solar components, direct and diffuse, it can be presumably used for predicting façades' annual solar irradiation at any location within the tested range of latitudes. With respect to monthly global irradiance, the relationship appears less consistent, affected by the increased sensitivity of the relationship of SVF with monthly direct irradiance to façade orientation and location's latitude, associated with the variations of solar altitude.
\end{abstract}

\section{Introduction}

Solar radiation is one of the renewable energy resources with the greatest potential as it is estimated that, upon certain conditions, it could contribute up to $27 \%$ of the global electricity production by 2050 (International Energy Agency, 2014). Unlike other renewable energy technologies, photovoltaic (PV) systems can be relatively easily implemented in the urban environment, integrated into new or existing buildings replacing conventional materials in roofs, walls and windows, or applied externally onto the building fabric (Peng et al., 2011).

Using building-integrated photovoltaics (BIPV) is an elegant way of generating electricity in a distributed manner (Pearce, 2002), exploiting otherwise unutilized surfaces instead of specifically devoting land (Mulcué-Nieto and Mora-López, 2015; Norton et al., 2011). In addition, BIPV produce electricity at the point of use limiting losses and other implications associated with transmission and distribution (Paatero and Lund, 2006). On-site energy generation is essential for achieving the "Zero Energy Buildings" target (Kanters and Horvat, 2012) and will be a requirement for all new buildings in the European Union after 2020 (EPBD, 2010). Furthermore, PVs located in urban areas are commonly grid-connected feeding all, or surplus electricity produced directly to an electricity network offsetting total urban demands (Mulcué-Nieto and Mora-López, 2014).

A major factor determining the solar electricity yield and economic feasibility of a PV system is the availability of solar radiation as determined by latitude and climate, as well as the placement and position of the PV module in the urban setting. Aiming to maximize solar access, roofs are preferable for the implementation of PVs compared to façades, as they allow more optimal placement (i.e. orientation and tilt, especially on flat roofs) and are usually less shaded. Correspondingly, an important number of studies on solar energy potential in urban environments focuses exclusively on roofs (e.g. Assouline et al., 2017; Bergamasco and Asinari, 2011; Mavromatidis et al., 2015; Hachem et al., 2012; Wiginton et al., 2010; Wittmann et al., 1997).

Nonetheless, with façades comprising the greatest part of urban buildings' surface, their solar irradiation represents a considerable percentage of cities' solar potential (Esclapés et al., 2014; Redweik et al., 2013) and their exploitation becomes critical for the attainment of energy efficiency targets at building and urban scales. According to a study for Lisbon, Portugal, the PV potential on façades and roofs can

\footnotetext{
* Corresponding author at: Kent School of Architecture, University of Kent, Marlowe Building, CT2 7NR Canterbury, United Kingdom.

E-mail address: C.Chatzipoulka@kent.ac.uk (C. Chatzipoulka).
} 
reach $50-70 \%$ of the areas' total electricity demand, with the contribution of façades being significant in the winter, as well as in the morning and afternoon hours during the summer (Brito et al., 2017). In countries at higher geographical latitudes, such as in Scandinavia, the role of façades in generating adequate amounts of electricity may be even more significant, provided that the urban design is optimized for preventing their overshadowing (Lobaccaro et al., 2017). At building scale, a study in Montreal, Canada, showed that PVs integrated in roofs and façades of residential buildings can produce up to $90 \%$ of the electricity demand of a four-story building, decreasing with increasing building height to $50 \%$ for twelve stories high (Hachem et al., 2014). Besides a large contribution to the annual solar energy potential, PVs integrated in the façades of a building in Spain resulted in a more stable production throughout the year compared to those on the flat rooftop (Sánchez and Izard, 2015). This is in line with another study examining monthly average yields of PV modules at various European locations, mounted at different angles, which ascertains that vertical ones present a more balanced seasonal profile (Šúri et al., 2007). As a result, it can be argued that adopting a wider range of recommended façade orientations for the installation of PVs ensures a more even distribution of electricity production in the day, especially at middle latitudes.

Façades are visible and fully functional parts of building envelopes providing daylight, natural ventilation and views through windows, which imposes restrictions on the application of BIPV systems. With PV technology advancing rapidly, a variety of quality products available nowadays achieve an increased architectural integration, aesthetically (e.g. variety of colours, levels of transparency) as well as functionally (e.g. rain-screen cladding, providing solar and glare protection). Further research and development of BIPV products are anticipated to play a key role in the establishment of façades as energy generators, particularly for of existing buildings (Jelle, 2015). For instance, the retrofitting of typical residential buildings in Italy by applying coloured PV panels on the façades as cladding material improved both their energy performance and appearance (Evola and Margani, 2016), while the PV potential in building façades replacing conventional shading devices with BIPV awnings or louvres was investigated for Greece (Karteris et al., 2014).

Forecasting solar irradiation of façades remains critical for ensuring the economic feasibility of PV applications and can be very challenging in urban areas, where façades' solar irradiation varies significantly due to the combined effect of orientation and degree of obstruction by nearby buildings (Yun and Steemers, 2009). In this context, information about annual solar irradiation or solar losses as a function of surface orientation and inclination (e.g. in Cronemberger et al. (2012) for Brazilian cities) is indicative but omits potentially significant shading losses. For the latter to be considered, annual solar simulations are required based on the actual 3D urban geometry.

Although the use and scope of solar modelling has increased, this is still mostly performed by researchers and specialist consultants. A study on the architectural barriers to spreading solar energy systems into the general building practice showed that only $2 \%$ of the architects were satisfied with the existing tools (Wall et al., 2012). Among the major challenges identified by the survey was the architects' poor skills of energy and solar simulation tools, as well as that the available tools being commonly perceived as complex, time-consuming or simply not suitable for the early design phase. Acknowledging the significance of considering BIPV early in the design process, a method which would address architects' need for a simpler and quicker evaluation of annual solar irradiation of building surfaces could strongly promote the solar energy production within cities.

This study examines to what extent solar irradiance on vertical façades can be predicted using solely two parameters, openness to the sky, as expressed by the sky view factor, and orientation. Past studies, employing statistical analysis, have shown a strong negative relationship between degree of sky obstruction, associated with built density and compactness, and façades' solar irradiation (Chatzipoulka et al.,
2016; Mohajeri et al., 2016); however, their findings refer to average values over entire urban areas, neglecting the orientation parameter.

\section{Background and objectives}

Initially introduced by urban climatologists, the sky view factor (SVF) is a geometric measure that expresses openness of a point to the sky and thus, capability to emit and receive longwave radiation to and from the sky. It is calculated as a ratio with its value ranging from 0 to 1 , denoting a totally obstructed and unobstructed point respectively. For vertical façades, the maximum value is 0.5 as an unobstructed façade can be seen only by half of the sky vault. In the literature, the SVF is equally considered as an urban geometry variable, for instance, investigating its relationship with spatial variations of urban air and surface temperatures (Eliasson, 1996; Giridharan et al., 2007), and as performance indicator evaluating environmentally built forms (Project PREcis, 2000; Ratti et al., 2003). With respect to façades, SVF values are strongly associated with illuminance levels and daylight availability (Cheng et al., 2006; Zhang et al., 2012), whereas, the relation between SVF and solar availability is less established (Robinson, 2006).

In the past, SVF measurements were feasible only in situ and at one point each time, using special equipment such as fish-eye cameras (Steyn, 1980). Nowadays, an increasing number of solar and thermal analysis models perform accurate SVF calculations as part of their simulations, over entire urban surfaces and at different spatial resolutions. Compared to solar irradiance simulations, the calculation of SVF is much faster and requires one input, the 3D urban geometry information.

This paper investigates extensively the relationship of SVF with solar irradiance by façade orientation, addressing different research objectives. First, it examines whether the SVF can be employed for estimating solar energy potential on building façades at different locations, i.e. combinations of latitude and climate. For this reason, solar irradiance simulations are performed for three locations in Europe, Athens, London and Helsinki, with special emphasis on the annual global irradiance results. Second, it provides graphical tools to architects working in the three cities for calculating annual global irradiation of a façade, or a section of it, based on its average SVF value and azimuth degree. Third, it broadens our understanding about the relationship between SVF and façade solar availability by examining separately the three solar components, i.e. direct, diffuse from the sky and reflected by buildings irradiances. Finally, the repetition of the analysis for a winter and summer month, January and July, aims to investigate the effect of varying solar altitude on the relationship of SVF with façades' solar irradiation, especially its direct component.

\section{Methodology}

\subsection{Cases studies}

The study is based on the analysis of 24 urban forms, of $500 \times 500 \mathrm{~m}$ area each, which were selected from three areas of London: central, west and north areas (Fig. 1). These represent urban environments of different built density with the studied forms covering values from 3 to $22 \mathrm{~m}^{3} / \mathrm{m}^{2}$ (total built volume within the site over the site area). The criteria for their selection and the results from their geometric analysis are presented in Chatzipoulka et al. (2016). For the naming of the urban forms (as presented in Fig. 2) the letter denotes the area to which an urban form belongs (C, W, N for central, west, north areas, respectively), and the number derives from its position in the area's map (starting from top left corner and counting from top to bottom).

\subsection{SVF and solar irradiance simulations}

Solar simulations were performed in the PPF software, a powerful 


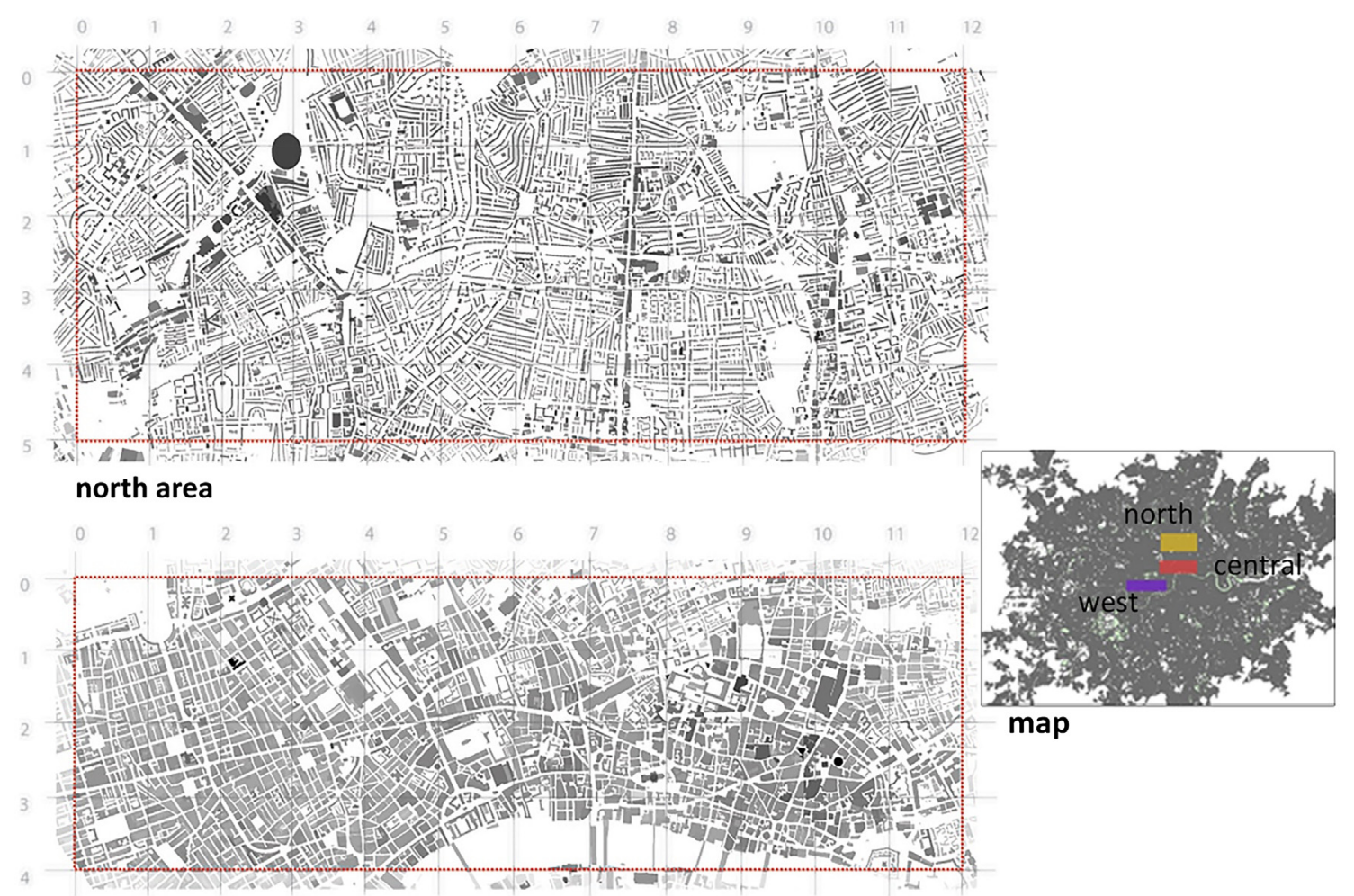

central area

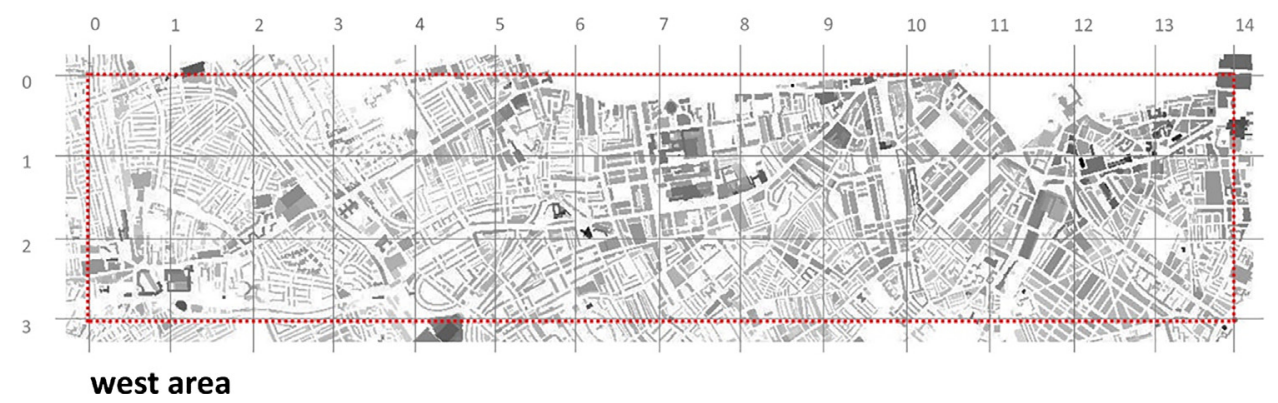

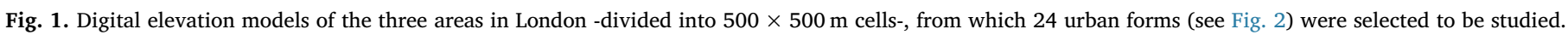

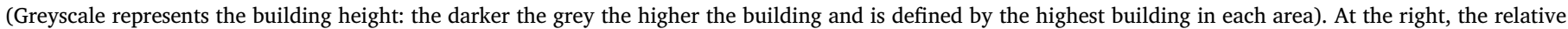
position of the three areas within the Greater London Urban Area.

tool which has been employed by several studies, so far (Chatzipoulka et al., 2016; Cheng et al., 2006; Montavon et al., 2004, Project PREcis, 2000). PPF is based on the RADIANCE ray-tracing programme (Ward Larson and Shakespeare, 1998) and uses sky models which represent average radiance distributions of the sky vault for a given time period (Compagnon, 2004).

Irradiation simulations were run for three locations representing different geographical latitudes within Europe. Besides London $\left(51^{\circ} 30^{\prime} \mathrm{N}\right)$, the original location of the studied urban forms, two more cities were tested, Athens $\left(37^{\circ} 58^{\prime} \mathrm{N}\right)$ and Helsinki $\left(60^{\circ} 10^{\prime} \mathrm{N}\right)$. For each city, three sky models were produced, the annual one and those for January (winter month) and July (summer month). Climatic data, namely hourly direct normal and diffuse horizontal irradiance values, were obtained from METEONORM software (Remund et al., 2015) for a typical year and processed statistically to build up nine sky models (Fig. 3). In the generation of the sky models, only daytime hours are considered, i.e. all hours from sunrise to sunset on a day, which are provided in Table 1 along with mean direct and diffuse horizontal irradiances, by location and period.

The 3D geometry of the studied urban forms were reproduced in a CAD software, including the surrounding buildings, and inserted in PPF in .dxf format (Fig. 4). SVF and mean irradiances $\left[\mathrm{W} / \mathrm{m}^{2}\right]$ values were computed for points on a grid of 2-meter spatial resolution, adjusted onto the surfaces of the models. Direct (Id), diffuse from the sky (Is) and reflected by buildings (Ib) irradiances were computed separately, whereas, global (Ig) irradiance is calculated as the sum of three solar components as described below:

$I g=I d+I s+I b,\left[\mathrm{~W} / \mathrm{m}^{2}\right]$

For the calculation of the reflected solar component, the albedo value was kept to default, 0.2 , for all the surfaces of the models, and the number of bounds of the solar ray is restricted to 1 , instead of 2 which is commonly used in solar modelling. The latter was necessary as to reduce the computational time required, given the number of simulations to be performed ( 24 urban forms by nine sky models), size and complexity of the urban forms, and fine spatial resolution opted for in the simulations. A sensitivity analysis, which was conducted for four urban forms of different built density (i.e. C27, C16, W27 and N44) and three sky models of London, showed that by increasing the number of bounds to two, the increase in average reflected irradiance values was very limited. More precisely, the absolute increase varied from 0.3 to $1.6 \mathrm{~W} /$ $\mathrm{m}^{2}$ with smallest and largest differences being found in January and July, respectively. The percentage of the reflected solar component in the average global irradiance increased by no more than $1.6 \%$, and 


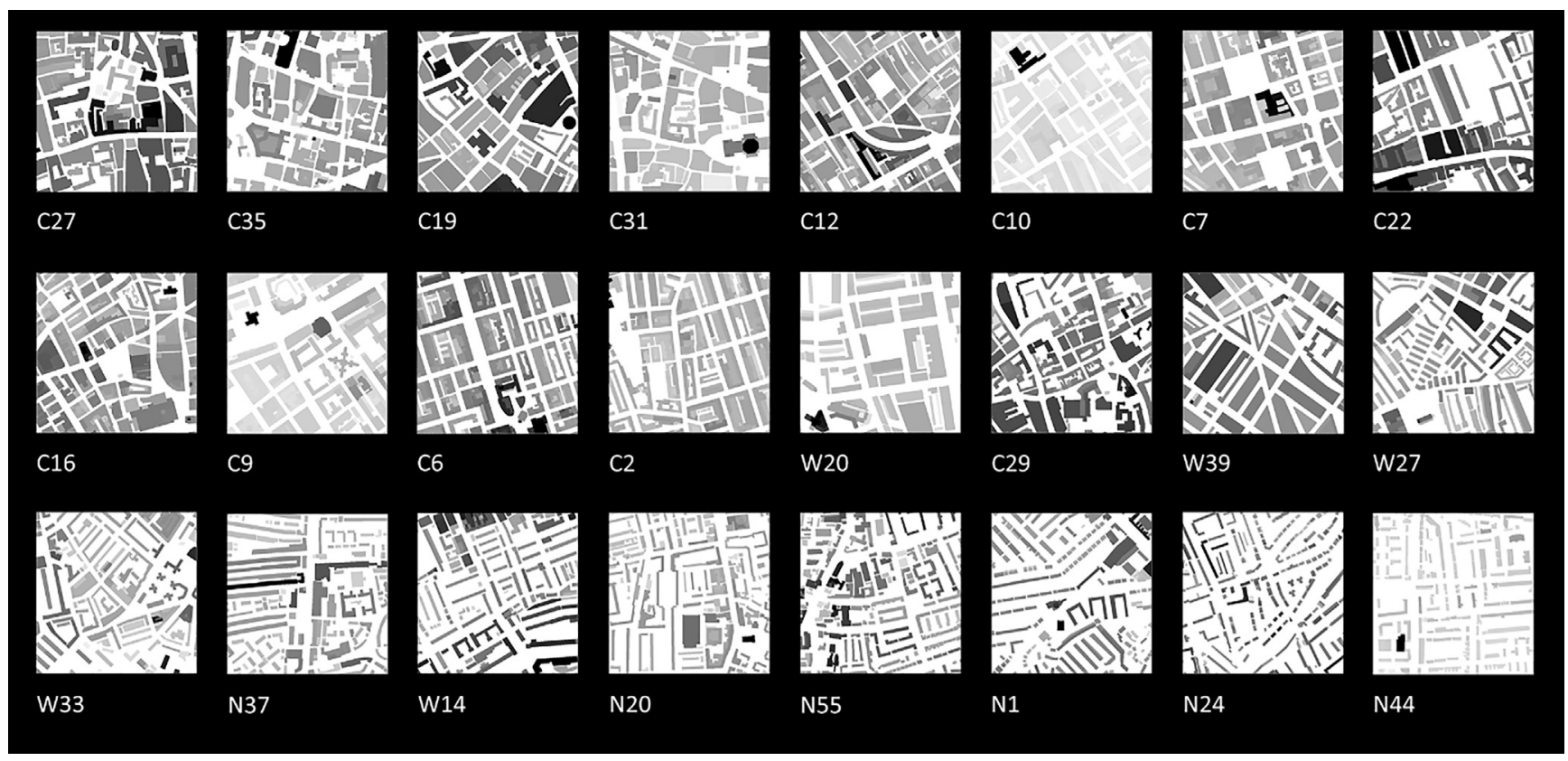

Fig. 2. Digital elevation models of the 24 urban forms considered in the analysis, in decreasing order of density. (Greyscale is different for each urban form, defined by its highest building).

ATHENS

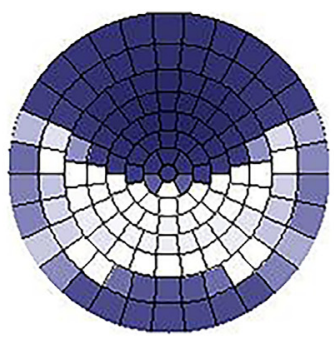

Year

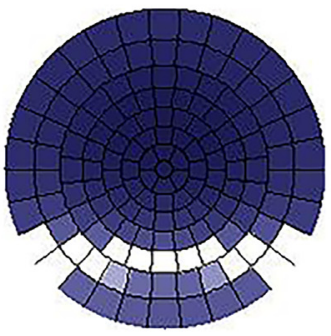

January

July
LONDON
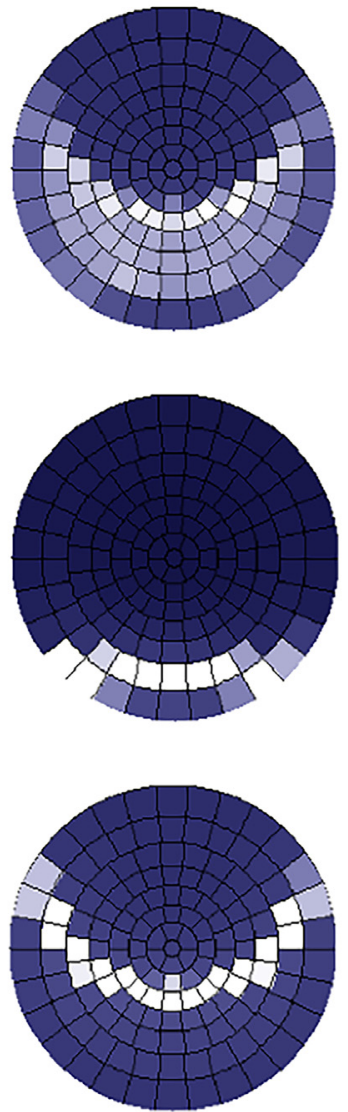

HELSINKI
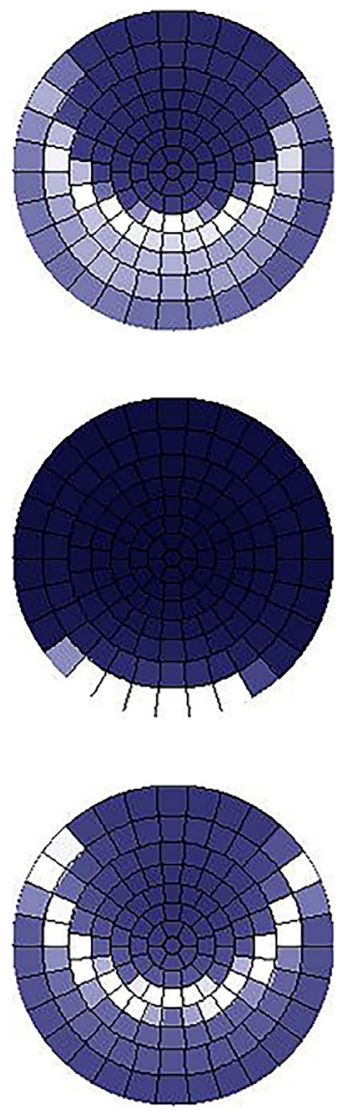

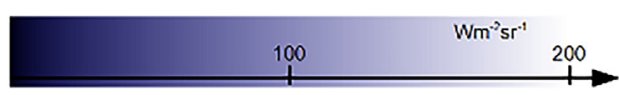

Fig. 3. Stereographic views of the radiance distribution on the sky vault for nine sky models generated for three cities, Athens, London and Helsinki (from left to right), for the entire year, January and July (from top to bottom). 
Table 1

Daytime hours, mean direct and diffuse horizontal irradiances for Athens, London and Helsinki for the three periods analysed.

\begin{tabular}{|c|c|c|c|}
\hline & Year & January & July \\
\hline \multicolumn{4}{|l|}{ Athens } \\
\hline Daytime hours, [h] & 4397 & 288 & 464 \\
\hline mean direct horizontal irradiance, $\left[\mathrm{W} / \mathrm{m}^{2}\right]$ & 265 & 170 & 372 \\
\hline mean diffuse horizontal irradiance, $\left[\mathrm{W} / \mathrm{m}^{2}\right]$ & 139 & 90 & 139 \\
\hline \multicolumn{4}{|l|}{ London } \\
\hline Daytime hours, [h] & 4317 & 249 & 489 \\
\hline mean direct horizontal irradiance, $\left[\mathrm{W} / \mathrm{m}^{2}\right]$ & 102 & 32 & 157 \\
\hline mean diffuse horizontal irradiance, $\left[\mathrm{W} / \mathrm{m}^{2}\right]$ & 120 & 52 & 136 \\
\hline \multicolumn{4}{|l|}{ Helsinki } \\
\hline Daytime hours, [h] & 4215 & 182 & 534 \\
\hline mean direct horizontal irradiance, $\left[\mathrm{W} / \mathrm{m}^{2}\right]$ & 101 & 9 & 137 \\
\hline mean diffuse horizontal irradiance, $\left[\mathrm{W} / \mathrm{m}^{2}\right]$ & 120 & 32 & 167 \\
\hline
\end{tabular}

reduced with decreasing built density. Nonetheless, the sensitivity analysis concerned London and average values over entire urban forms. It is acknowledged that the relative impact of the minimum number of solar bounds may vary with façade orientation and be more significant in Athens, especially for urban forms of high built density. In any case, setting the minimum number of solar bounds is a limitation of the reflected irradiance simulations and needs to be considered when interpreting the respective results.

\section{Results}

\subsection{Average façade SVF and solar irradiance values by urban form}

Average façade SVF and solar irradiance values were calculated by urban form, considering all the façade points in each of them. Average façade solar irradiances were computed for all the nine sky models. Fig. 5a-c illustrates average irradiances by urban form, as computed for the annual sky models of Athens, London and Helsinki. The urban forms are ranked, from left to right, in decreasing order of built density. As implied by the slope of the SVF lines, the relationship between the average façade SVF and the density of the urban forms is strongly negative with the coefficient of determination $\left(\mathrm{R}^{2}\right)$ at 0.92 . The coloured bars allow the comparison of the percentages in which the average annual global (i.e. total) irradiation of the façades consists of direct, sky diffuse and reflected solar radiation in the three cities. Note that, since the global irradiance expresses the sum of the three solar components, its statistical relationship with the SVF is determined by the relationship of each solar component with the SVF, weighted by their percentages.

In London and Helsinki, the average annual façade global irradiance constantly consists of direct radiation by $42-43 \%$, sky diffuse by $44-45 \%$ and reflected by $13-14 \%$. In other words, the sky diffuse radiation constitutes its greatest part, but still the contribution of the direct radiation is equally important. As seen in Table 1, the annual mean horizontal irradiances are similar in London and Helsinki, and there is a fair balance between the direct and diffuse components. In contrast, in Athens, the direct solar radiation exceeds by far the diffuse one, which affects the synthesis of their total irradiation with direct, sky diffuse and reflected radiations comprising $53-56 \%, 30-31 \%$, and $14-16 \%$, respectively, of the average annual façade global irradiance.

Similarly, the percentages of the three types of irradiance in the average façade global irradiance in January and July are related to the proportion of the available direct and sky diffuse radiations in the respective month at each location (see Table 1). Unlike the entire year though, their percentages vary significantly among the studied urban forms, clearly influenced by their built density.

Next, the relationships between average - by urban form - façade SVF and solar irradiances were examined through linear regression analysis. The $\mathrm{R}^{2}$ results in Table 2 indicate a significantly strong correlation with all the three types of irradiance comprising global irradiance, i.e. direct, diffuse and reflected. So, unsurprisingly, the relationship between SVF and global irradiance was found to be almost perfectly linear $\left(\mathrm{R}^{2}>0.9\right)$ in all the cases.

It should be noted that the extremely high $\mathrm{R}^{2}$ values do not refer to reality but are related to the methodology followed. First, the solar simulations take into account the interaction of the sky models with the 3D urban geometries, omitting any other parameter that may be significant in real contexts, such as materials and vegetation. In this regard, a significant correlation between SVF and solar irradiance is, up to a point, expected. Second, the relationship may be strengthened by the wide range of built densities and in turn, SVF values, featuring in the 24 urban forms. Moreover, the statistical results are affected by the averaging of the simulated values by urban form. As ascertained in the following section, when the relationships are tested for different façade orientations, only that between SVF and diffuse irradiance is consistently very strong. Combining the above, it is deemed reasonable that the direct, diffuse and reflected radiation received on average by the facades of an urban form is strongly related to their average openness to the sky.

The relationship the strength of which varies the most is that of SVF with direct irradiance, denoting its sensitivity to the varying - with latitude and time period - solar geometry. Although it is statistically significant in all the nine cases, the correlation appears stronger in the entire year than in January and July. This is explained by the annual sun paths, which contain all the possible positions of the sun -by location-, covering a great part of the sky. In other words, the longer the time period considered, the more the openness to the sky (i.e. the SVF) tends to approach the exposure to the sun. Another interesting point is that the lowest $R^{2}$ values are found for the case of Helsinki in January $\left(R^{2}=0.791\right)$, and Athens in July $\left(R^{2}=0.823\right)$, which represent the two sun paths of the lowest and highest average solar altitudes, respectively.
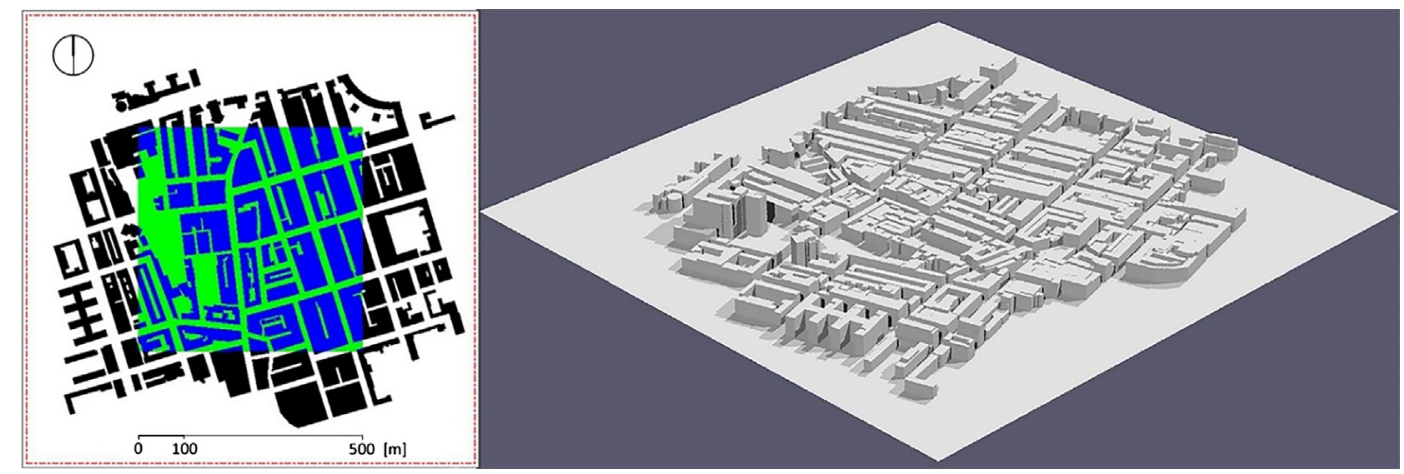

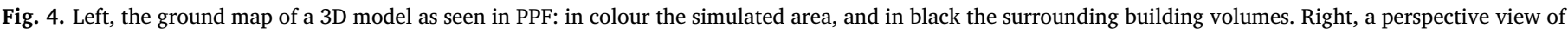
the same model. 


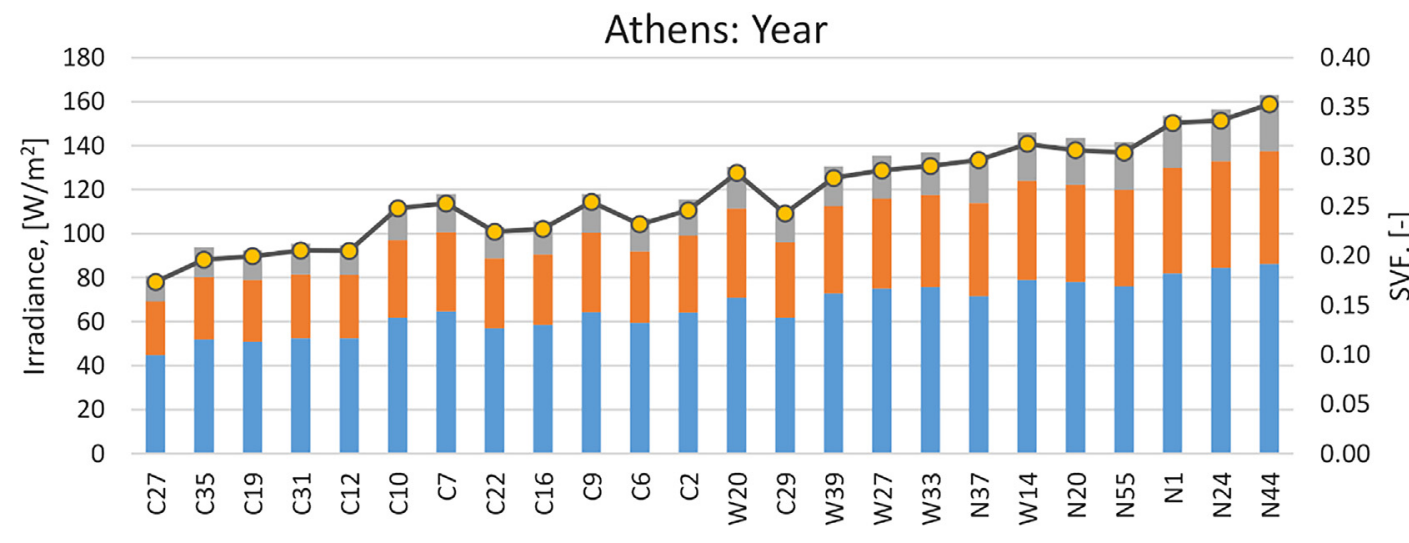

Direct Diffuse Reflected $\multimap$ SVF

(a)

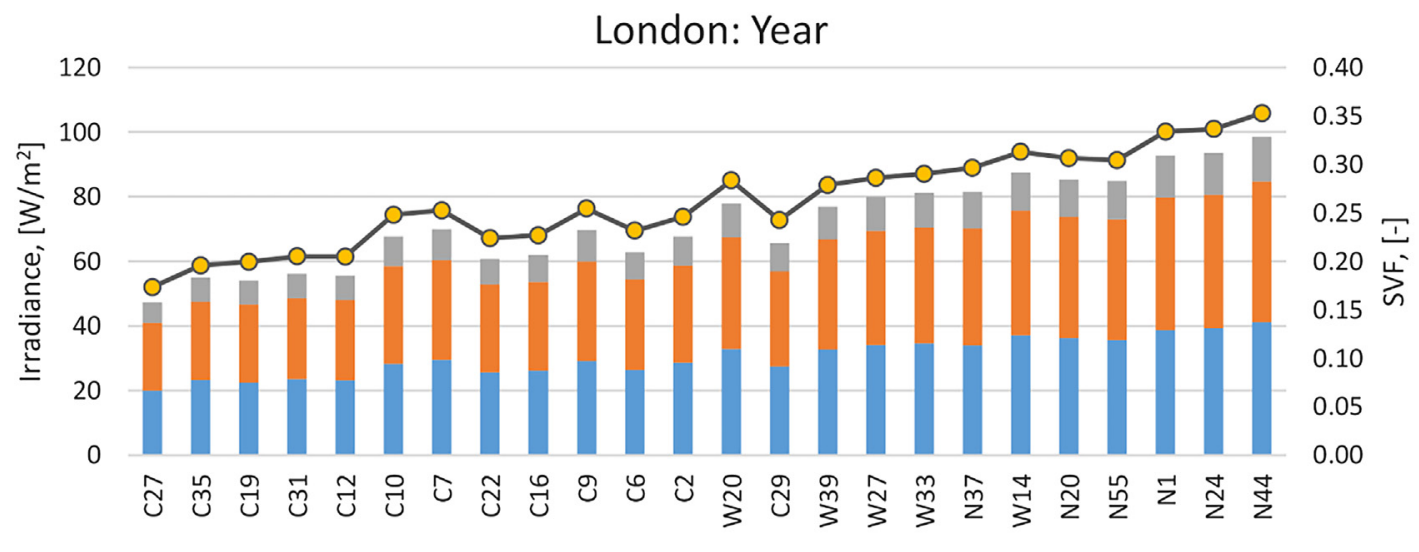

(b)

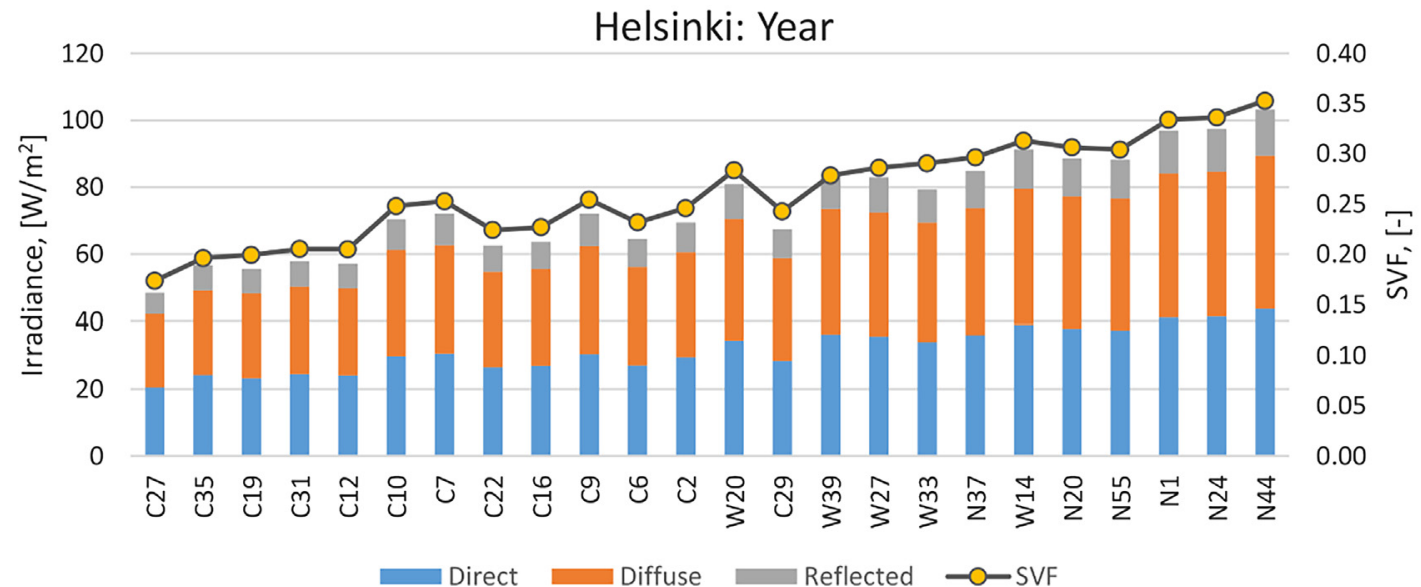

(c)

Fig. 5. Average façade SVF (dots) and annual global, direct, diffuse and reflected irradiances (bars) by urban form, in Athens (a), London (b) and Helsinki (c).

Table 2

The $\mathrm{R}^{2}$ describing the strength of the linear relationship between average façade SVF and average façade solar irradiances (global Ig, direct $I d$, diffuse $I s$ and reflected Ib) in the 24 urban forms.

\begin{tabular}{lllllllllllll}
\hline & Athens & \multicolumn{9}{c}{ London } & \multicolumn{9}{c}{ Helsinki } \\
\cline { 2 - 12 } & Ig & Id & Is & Ib & Ig & Id & Is & Ib & Ig & Id & Is & Ib \\
\hline Year & 0.996 & \multirow{2}{*}{0.986} & 0.999 & 0.984 & 0.999 & 0.997 & 1.000 & 0.995 & 0.991 & 0.988 & 0.993 & 0.982 \\
January & 0.979 & 0.967 & 0.994 & 0.979 & 0.985 & 0.966 & 0.997 & 0.988 & 0.943 & 0.791 & 0.995 & 0.964 \\
July & 0.960 & \multirow{2}{*}{0.823} & \multirow{2}{*}{0.999} & 0.987 & 0.996 & 0.977 & 1.000 & 0.995 & 0.998 & 0.987 & 0.999 & 0.990 \\
\hline
\end{tabular}


Hence, the relationship between façade SVF and available direct radiation may be affected by latitude, time period, and associated solar altitudes, but not in a consistent way. The above findings are further explored by examining these relationships by façade orientation in the following section.

\subsection{Façade SVF and solar irradiances by orientation}

In the previous section, the average façade SVF of the urban forms was found to correlate significantly well with the average values of all four types of solar irradiance, independently of location and time period. Nonetheless, the averaging of the values over entire urban areas may suppress considerable variations of the studied relationships occurring at different orientations, especially, with respect to direct solar radiation. For this reason, the statistical analysis was repeated testing the same relationships by façade orientation. Specifically, 30 orientation sectors, at $12^{\circ}$ azimuth intervals, were considered that correspond to the patches into which the perimeter of the sky models is divided (see Fig. 3). The numbering of the orientations moves clockwise from North (Orientation 1: $-6 \leq$ azimuth $<6$ ).

The statistical analysis was based on all the façade points in the 24 urban forms aggregated into 30 groups according to their azimuth degree. For each case, i.e. location and period, four sets of 30 groups were created; each set includes the pairs of SVF and one type of solar irradiance values (global, direct, diffuse and reflected) from all the urban forms, grouped into 30 orientations. In total, 1080 regression analysis tests (i.e. 30 orientations by four types of irradiance by nine cases) were performed using as sample thousands of façade points. The $\mathrm{R}^{2}$ results are plotted into polar charts and presented by city and period in Fig. 6 . The closed coloured lines depict the variations of the $\mathrm{R}^{2}$ with orientation, for global (blue), direct (red), diffuse (magenta) and reflected (cyan) irradiances; the $\mathrm{R}^{2}$ values are scaled from the centre outwards, with the centre denoting 0 and the outer circle 1 .

\subsubsection{Results regarding annual solar irradiances}

The first row of polar charts in Fig. 6 show the strength of the linear relationship of the SVF with the annual solar irradiances by façade orientation, in Athens, London and Helsinki (i.e. put in increasing order of geographical latitude). As seen, these are very similar to each other implying a limited effect of latitude and climate. With respect to the annual sky diffuse irradiance, its relationship with the SVF is almost perfectly linear independently of orientation and location, with the magenta lines almost coinciding with the outer circle. This is expected because the SVF measures the openness of a point to the sky and the distribution of diffuse radiance over the sky vault is relatively uniform. Hence, the amount of diffuse radiation that the point receives is proportional to its SVF value. Regarding the annual direct and reflected irradiances, the shapes of the lines, red and cyan, are also very similar for the three cities. The relationship between SVF and direct irradiance is clearly affected by façade azimuth; it is stronger at south orientations and becomes weaker moving to North. Importantly, the $\mathrm{R}^{2}$ is consistently above 0.8 for all major orientations facing the annual sun paths - approximately between $60^{\circ}$ and $300^{\circ}$ azimuth - in all three cities, despite that the availability of direct solar radiation in Helsinki and London is noticeably reduced compared to Athens. Examining the relationship between SVF and reflected irradiance, it is considerably weaker and the $\mathrm{R}^{2}$ is found to be higher in north-oriented façades than in south-oriented ones. Presumably, if the solar bounds were set to two in the simulations, instead of one, the differences between north and south orientations would be smaller; however, it would not change the overall results significantly, i.e. referring to global irradiance.

Finally, regarding the annual global irradiance, its relationship with the SVF is surprisingly stable in strength, with the $\mathrm{R}^{2}$ value being above 0.8 independently of orientation, at all the three locations examined. This is explained by the following: (i) the reflected solar component comprises a small percentage of the total irradiance received by building façades, and (ii) the solar irradiation of façades looking at north orientations is dominated by sky diffuse radiation. In conclusion, the SVF can adequately explain the variations of façades' annual global irradiation by orientation and, therefore, can be employed for predicting their annual solar energy potential.

\subsubsection{Results regarding solar irradiances in January and July}

The relationship of the SVF with the four solar irradiances in 30 façade orientations was also examined in January and July in order for the results to be associated with specific solar altitudes, given that for a certain orientation the solar altitude does not vary a lot during a month. As before, the linear regression results are plotted in polar charts showing the $\mathrm{R}^{2}$ obtained by orientation, for global, direct, diffuse and reflected irradiances (Fig. 6). As expected, the relationship of the SVF with the monthly diffuse irradiances appears almost perfectly linear in all the cases. Regarding the reflected irradiance, the $\mathrm{R}^{2}$ profiles are very similar for the three locations, by month. In January, for orientations facing the south half of the horizon, the $\mathrm{R}^{2}$ is close to zero indicating no correlation between SVF and reflected irradiance; for the other half, the $\mathrm{R}^{2}$ is relatively higher but still denotes a very weak relationship. In July, the correlation appears stronger and the $\mathrm{R}^{2}$ difference between northand south-facing orientations reduces; however, the $\mathrm{R}^{2}$ does not exceed 0.6 at any orientation.

The only relationship that presents significant differences when comparing the three locations is that of SVF with the direct irradiance. Especially in January, its strength is clearly affected by the cities' latitudes, decreasing with increasing latitude. Comparing the $\mathrm{R}^{2}$ obtained for the same orientations, they are higher for Athens compared to London, and for London compared to Helsinki, with maximum values being close to $0.8,0.6$ and 0.3 , respectively, occurring in south orientations. Indicatively, the solar altitude at midday in January is on average $31.8^{\circ}$ in Athens, $18.3^{\circ}$ in London, and $9.5^{\circ}$ in Helsinki. Furthermore, as ascertained in all the three cases, moving from South to North, the strength of the relationship gradually diminishes to zero.

In July, when average solar altitudes are significantly higher, the relationship between SVF and direct irradiance becomes much stronger, and the differences among the three cities are less evident. Interestingly, in the summer month, the correlation is considerably higher in east and west orientations, rather than in south ones. Moreover, in south orientations, the $\mathrm{R}^{2}$ increases with increasing latitude: for south-oriented façades (azimuth: $174-186^{\circ}$ ), the $\mathrm{R}^{2}$ is approximately 0.6 for Athens, 0.7 for London, and 0.75 for Helsinki. Note that, in July, the average solar altitude at midday is $72.7^{\circ}, 59.2^{\circ}$ and $50.5^{\circ}$ at the three locations, respectively.

Combining the results of the analysis for the two months, it becomes evident that the strength of the relationship between SVF and direct solar irradiance is affected by increasing solar altitude; however, as first ascertained in Section 4.1, the effect of the latter changes. At relatively lower solar altitudes, such as occurring in January, the correlation was found to get stronger with increasing solar altitude, whereas, the opposite stands at higher altitudes, such as those characterising the month of July. The above observations indicate that there is a "critical" solar altitude angle for which the strength of the relationship between SVF and solar exposure is maximized. This is consistent with the findings of another study which investigated statistically the relation between average solar exposure of open spaces and average ground SVF (Chatzipoulka and Nikolopoulou, 2018). The existence of such a "critical" altitude angle is reasonable as, for the extreme solar altitudes of $0^{\circ}$ and $90^{\circ}$, the relationship becomes null: in the first case, all the façades are shaded, and in the second one, they are all orthogonally sunlit (i.e. get zero irradiance), no matter of their obstruction degree.

Finally, regarding the relationship between SVF and monthly global irradiances, the $\mathrm{R}^{2}$ profiles in Fig. 6 appears rather different for the three locations, reflecting the increased sensitivity of the SVF-monthly direct irradiation relationship to the varying solar altitude. In general, the results indicate that the SVF can predict better the annual than 
ATHENS

Year
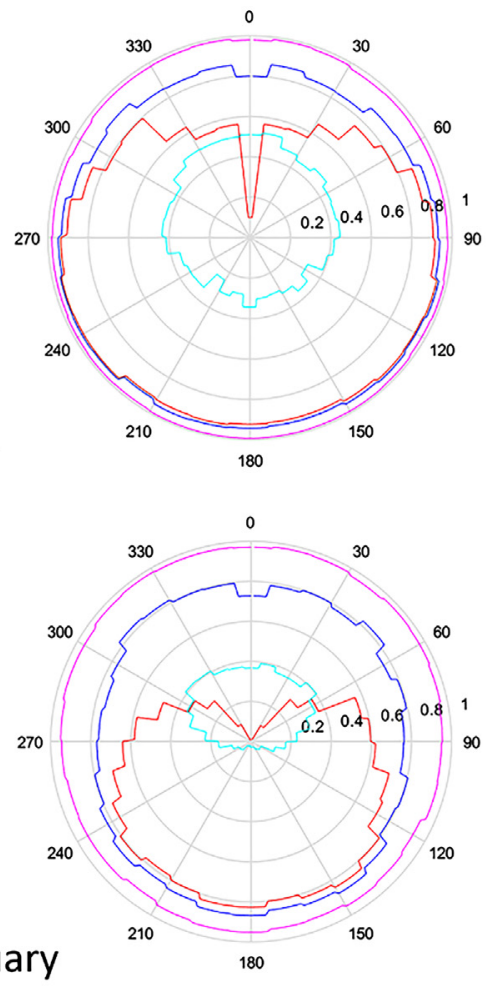

July

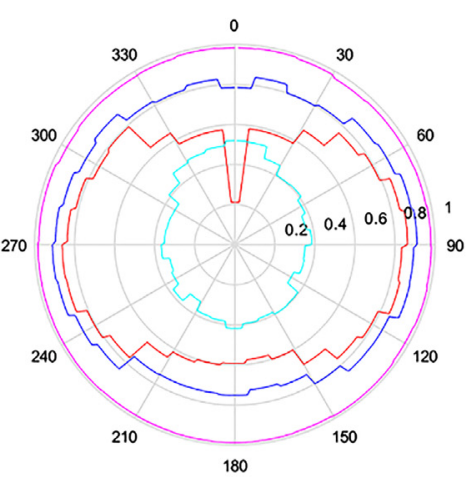

LONDON
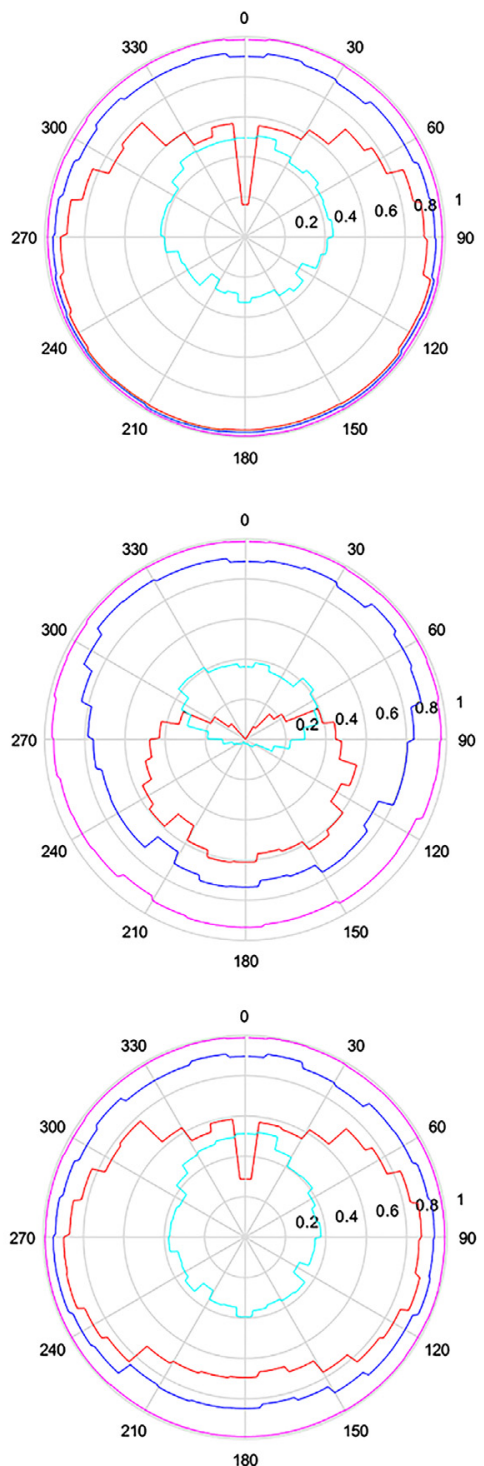

HELSINKI
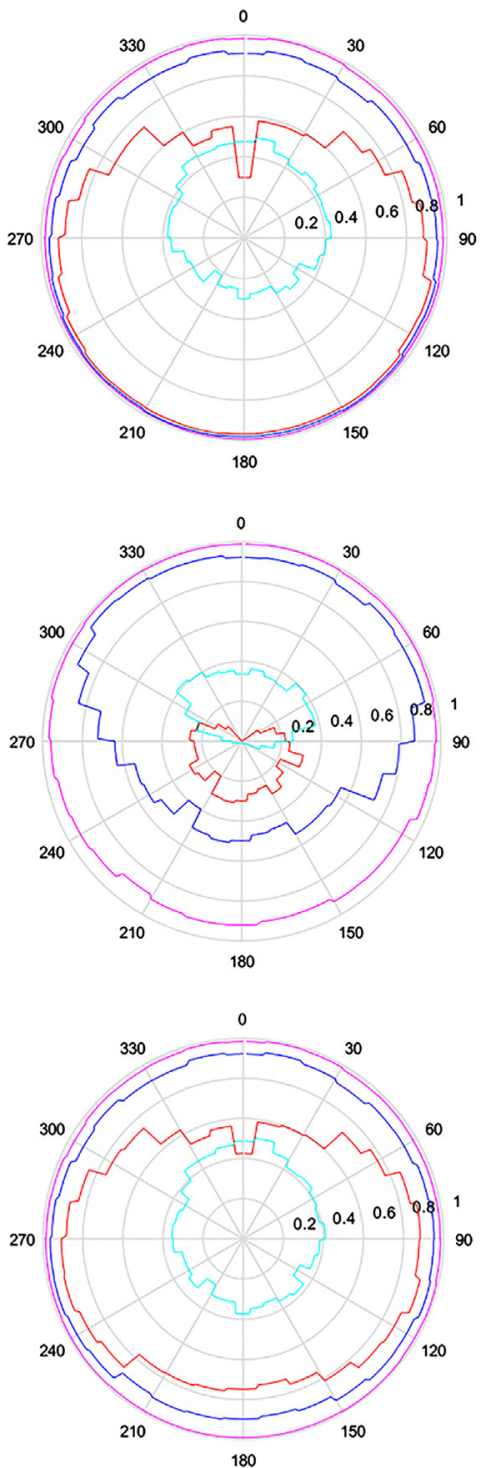

180

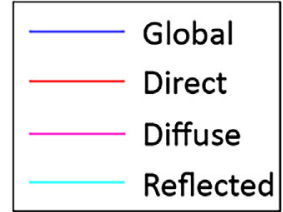

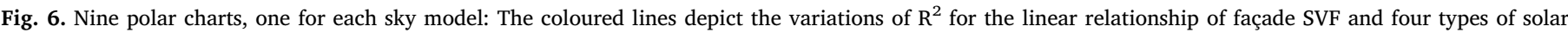
irradiance, in 30 orientations. The $\mathrm{R}^{2}$ value counts from the centre to the outer circle, i.e. $0-1$.

monthly global irradiation of façades by orientation.

\section{Predicting annual global irradiance on façades}

The efficiency of BIPV systems increases steadily taking advantage of developments in solar cells technology. Such a development is the improved low-illumination behaviour of third-generation photovoltaic cells like, for instance, the Dye-sensitized Cells (DSC) (Biyik et al., 2017; Jelle et al., 2012). The efficient exploitation of diffuse daylight by new BIPV products is particularly important for their productivity when applied into building façades which usually receive less direct radiation compared to roofs. Considering the above, it becomes apparent that the assessment of the PV potential in façades should take into account their global rather than direct irradiation. Since the relationship of the SVF with the annual façade global irradiance is found to be almost perfectly linear, independently of façade orientation, the SVF can be deemed as a good predictor of their solar energy/PV potential, at least for the range of latitudes tested.

This section provides graphical tools for architects based in Athens, London, and Helsinki, to estimate annual global irradiance on a vertical façade, or part of it, as a function of its azimuth degree and average SVF. For this purpose, the linear regression analysis was repeated setting the intercept to zero. This was necessary to calibrate the models considering that when SVF is zero, solar irradiance will be zero too. Note that, forcing intercept to zero affects imperceptibly the regression results with the absolute change in $\mathrm{R}^{2}$ being always smaller than $10^{-2}$. 
Table 3

Coefficients b (in $\mathrm{W} / \mathrm{m}^{2}$ ) for estimating annual global irradiance (Ig) and irradiation $(\mathrm{Gg})$ as function of SVF in different orientations, considering $\mathrm{Ig}=\mathrm{b} * \mathrm{SVF}$ and $\mathrm{Gg}=\mathrm{b} * \mathrm{SVF} * \mathrm{~h}$, where $\mathrm{h}$, the annual daytime hours in each city (provided in Table 1 ).

\begin{tabular}{|c|c|c|c|c|}
\hline Orient. & Azimuth & Athens & London & Helsinki \\
\hline North & $-6 \leq a<6$ & 189.29 & 137.78 & 141.84 \\
\hline 2 & $6 \leq a<18$ & 193.58 & 139.15 & 140.46 \\
\hline 3 & $18 \leq a<30$ & 214.89 & 146.54 & 146.83 \\
\hline 4 & $30 \leq \mathrm{a}<42$ & 262.64 & 168.23 & 166.21 \\
\hline 5 & $42 \leq \mathrm{a}<54$ & 306.58 & 188.10 & 185.41 \\
\hline 6 & $54 \leq \mathrm{a}<66$ & 347.19 & 206.98 & 203.90 \\
\hline 7 & $66 \leq \mathrm{a}<78$ & 403.99 & 234.95 & 232.46 \\
\hline 8 & $78 \leq a<90$ & 462.69 & 265.26 & 264.28 \\
\hline 9 & $90 \leq \mathrm{a}<102$ & 502.11 & 285.90 & 286.46 \\
\hline 10 & $102 \leq \mathrm{a}<114$ & 536.48 & 307.04 & 312.10 \\
\hline 11 & $114 \leq \mathrm{a}<126$ & 586.22 & 337.05 & 345.56 \\
\hline 12 & $126 \leq \mathrm{a}<138$ & 607.45 & 354.61 & 367.37 \\
\hline 13 & $138 \leq \mathrm{a}<150$ & 616.45 & 365.89 & 382.77 \\
\hline 14 & $150 \leq \mathrm{a}<162$ & 637.09 & 380.90 & 401.38 \\
\hline 15 & $162 \leq \mathrm{a}<174$ & 639.39 & 386.41 & 409.99 \\
\hline South & $174 \leq \mathrm{a}<186$ & 636.05 & 387.66 & 414.26 \\
\hline 17 & $186 \leq \mathrm{a}<198$ & 632.24 & 385.72 & 413.56 \\
\hline 18 & $198 \leq \mathrm{a}<210$ & 634.53 & 382.36 & 410.52 \\
\hline 19 & $210 \leq a<222$ & 626.41 & 375.85 & 404.10 \\
\hline 20 & $222 \leq a<234$ & 607.32 & 362.63 & 389.46 \\
\hline 21 & $234 \leq \mathrm{a}<246$ & 574.61 & 340.62 & 366.10 \\
\hline 22 & $246 \leq \mathrm{a}<258$ & 541.89 & 318.72 & 341.47 \\
\hline 23 & $258 \leq \mathrm{a}<270$ & 505.74 & 296.86 & 317.20 \\
\hline 24 & $270 \leq \mathrm{a}<282$ & 465.78 & 273.93 & 292.92 \\
\hline 25 & $282 \leq \mathrm{a}<294$ & 406.08 & 240.46 & 257.20 \\
\hline 26 & $294 \leq a<306$ & 342.99 & 208.34 & 222.78 \\
\hline 27 & $306 \leq \mathrm{a}<318$ & 305.40 & 190.27 & 202.75 \\
\hline 28 & $318 \leq \mathrm{a}<330$ & 252.19 & 164.82 & 174.61 \\
\hline 29 & $330 \leq a<342$ & 217.53 & 149.25 & 156.92 \\
\hline 30 & $342 \leq a<354$ & 194.95 & 139.81 & 145.96 \\
\hline
\end{tabular}

In total, 30 analytical models, one for each orientation sector, were generated for all the three cities and the multiplying factors, b coefficients, are listed in Table 3.

The linear models were next solved for 10 representative SVF values, from 0 to 0.5 , at 0.05 intervals, and the points were plotted on Cartesian axes as continuous curves. The graphs produced for the three cities are presented in Fig. 7a-c, and the suggested way of using them is as follows:

- identify the azimuth degree of the façade of interest on the horizontal axis;

- from that point, draw a normal line to intersect the curve representing SVF value closest to the average SVF of the façade;

- project the intersection point on the vertical axes to read the estimated annual mean global irradiance $\left[\mathrm{W} / \mathrm{m}^{2}\right]$ (left) and global irradiation $\left[\mathrm{kWh} / \mathrm{m}^{2}\right]$ (right).

To exemplify façade SVF values for different levels of built obstruction, average façade SVF for an ideal urban canyon of varying height-to-weight $(\mathrm{H} / \mathrm{W})$ ratio are computed and provided in Fig. 8. (Except for average SVF values referring to the entire façade height, average values by façade sections of constant height are also provided at the left.)

Furthermore, the graphs can be employed for identifying suitable façades, in terms of orientation and adequate SVF, for the application of solar active strategies. In this case, the use of the graphs is inverse: we identify the given threshold value on the vertical axis and draw through a normal, horizontal line. The sections of the curves above the threshold line represent the combinations of façade azimuth and SVF that ensure adequate annual solar irradiation for the relevant purpose. For instance, recent research, focusing on the European market and updated PV standards, suggests $600 \mathrm{kWh} / \mathrm{m}^{2}$ as an annual irradiation threshold for the implementation of PV on building envelopes (Zanchetta, 2017). Applying the threshold of $600 \mathrm{kWh} / \mathrm{m}^{2}$ on the graphs for Athens, London and Helsinki, potentially suitable façades can be easily identified at orientations between 36 and $324^{\circ}, 90$ and $276^{\circ}$ and 90 and $282^{\circ}$, respectively. Moreover, on a south-oriented façade $\left(\mathrm{a}=180^{\circ}\right)$, suitable locations for PV installations should have SVF at least 0.2 in Athens, 0.35 in London, and 0.33 in Helsinki.

Assuming a façade located in an ideal urban canyon (i.e. its obstruction is due to an opposite, infinitely long, parallel building of constant height), the maximal obstruction angle, $\theta_{\max }$, that can be tolerated to ensure a target SVF value, $S V F_{\text {target }}$, can be computed as:

$\vartheta_{\max }=\operatorname{asin}\left(1-2 \times S V F_{\text {target }}\right)$

As shown in Fig. 9, using a section view of the urban canyon, the above equation can serve to identify the upper section of a façade at all points of which the specified $S V F_{\text {target }}$ value is achieved. Indicatively, using the previous example, $0.2,0.35$ and 0.33 SVF values correspond to maximal obstruction angles $\theta_{\max }$ of $36.9^{\circ}, 17.5^{\circ}$ and $19.9^{\circ}$ respectively.

\section{Linear models derived from climatic data}

The study suggests that the annual global irradiation $\left(G_{g}\right)$ of a façade of azimuth $a$ can be predicted as a linear function of its average SVF in the following form: $\mathrm{G}_{\mathrm{g}}(a)=b$ *SVF. This was ascertained by analysing three case study cities, but, as discussed, can be assumed for all locations within the given range of latitudes, approximately $38-60^{\circ}$. Thus, it would be of great value, if the respective $b$ coefficients could be estimated solely from the climatic data of a location, avoiding the need for simulations. For this purpose, we calculated annual global irradiance for unobstructed vertical surfaces (i.e. $S V F=0.5$ ) oriented towards the centres of 30 orientation sectors considered, based on the climatic data of each city. Specifically, we used METEONORM software (Remund et al., 2015) to obtain global annual irradiation values $G_{g}$ for specific directions dir and the $b^{*}($ dir) $[-]$ coefficients were next calculated using the following formula:

$b^{*}($ dir $)=1000 \times G_{g}($ dir $) /(0.5 \times D T)$,

where $G_{g}($ dir $)$ is the annual global irradiation in $\mathrm{kWh} / \mathrm{m}^{2}$ computed by METEONORM for a vertical unobstructed façade oriented towards direction dir, and $D T$ is the number of daytime hours for the considered location (as listed in Table 1).

As shown in Fig. 10, when comparing the estimated coefficients $b^{*}$ with those derived from the simulations, their values appear in a fairly good agreement. Especially in the case of London, their relative difference fluctuates below $5 \%$ for most orientations from East to West; larger discrepancies are observed in north orientations with the largest one being $17.6 \%$. For Athens, larger differences - in absolute values are observed in south orientations for which the b coefficients obtained from the simulations are higher to the ones calculated with METEONORM. Their relative difference is equally important in south and north orientations without exceeding $14.7 \%$. Among the three cities, Helsinki is the case with the greatest discrepancies between the values of the two coefficients. Moreover, in Helsinki, the $b^{*}$ coefficient is always higher than that derived from the simulations, by $6 \%$ (south) up to $26 \%$ (north-east).

The better agreement between the two coefficient values for London may be related both to the latitude of the location, i.e. middle among the three tested, as well as its climate, i.e. balance of direct and diffuse solar irradiance. Overall, the results of the comparison are encouraging; however, further research is required in order for that simplified method of predicting annual solar irradiation of façades to be validated and established. 
Athens
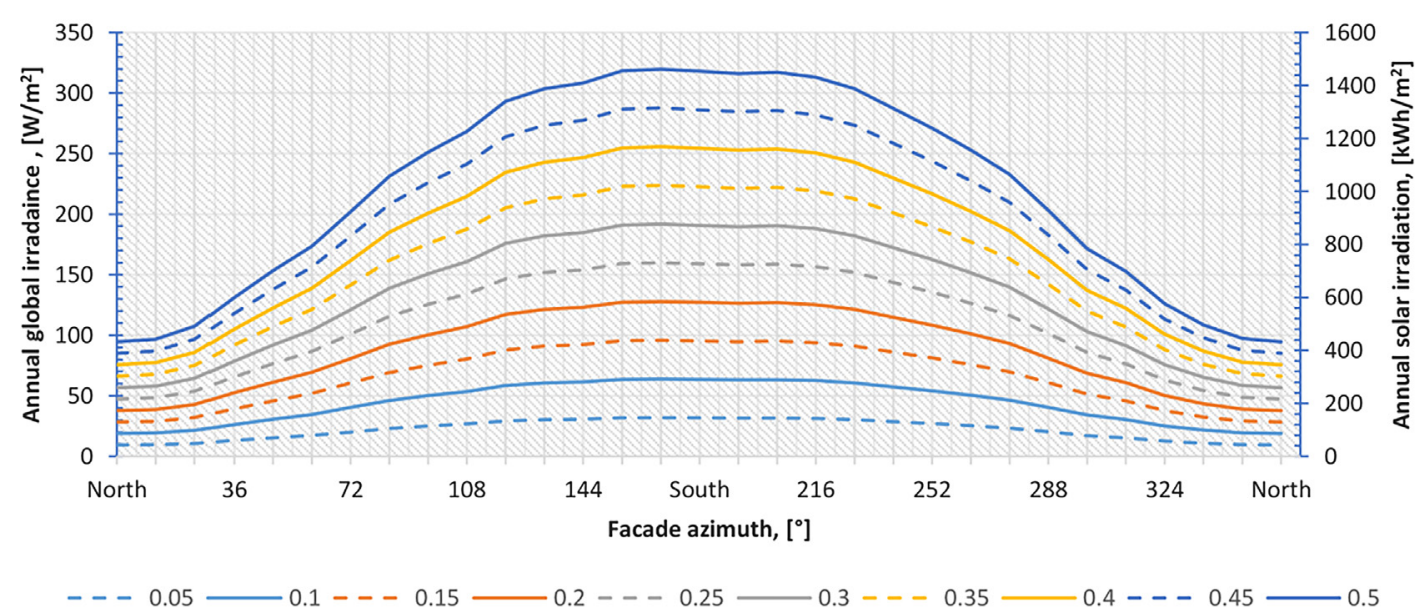

(a)

London

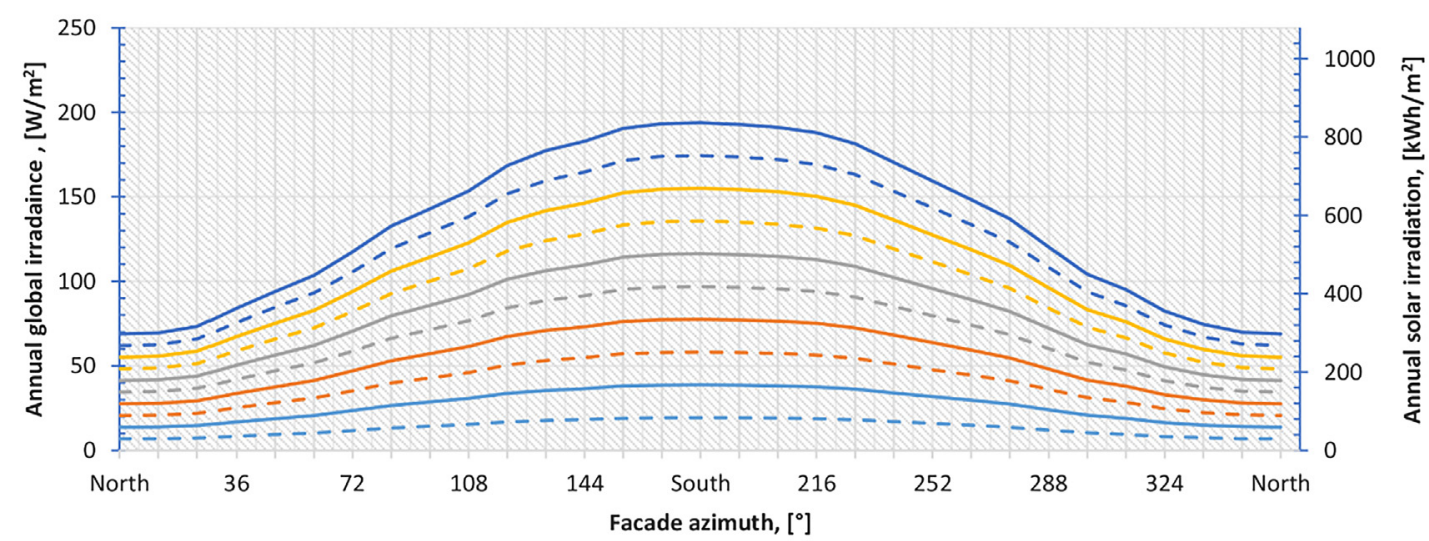

$---0.05-0.1--0.15-0.2--0.25-0.3--0.35-0.4--0.45 \longrightarrow 0.5$

(b)

Helsinki

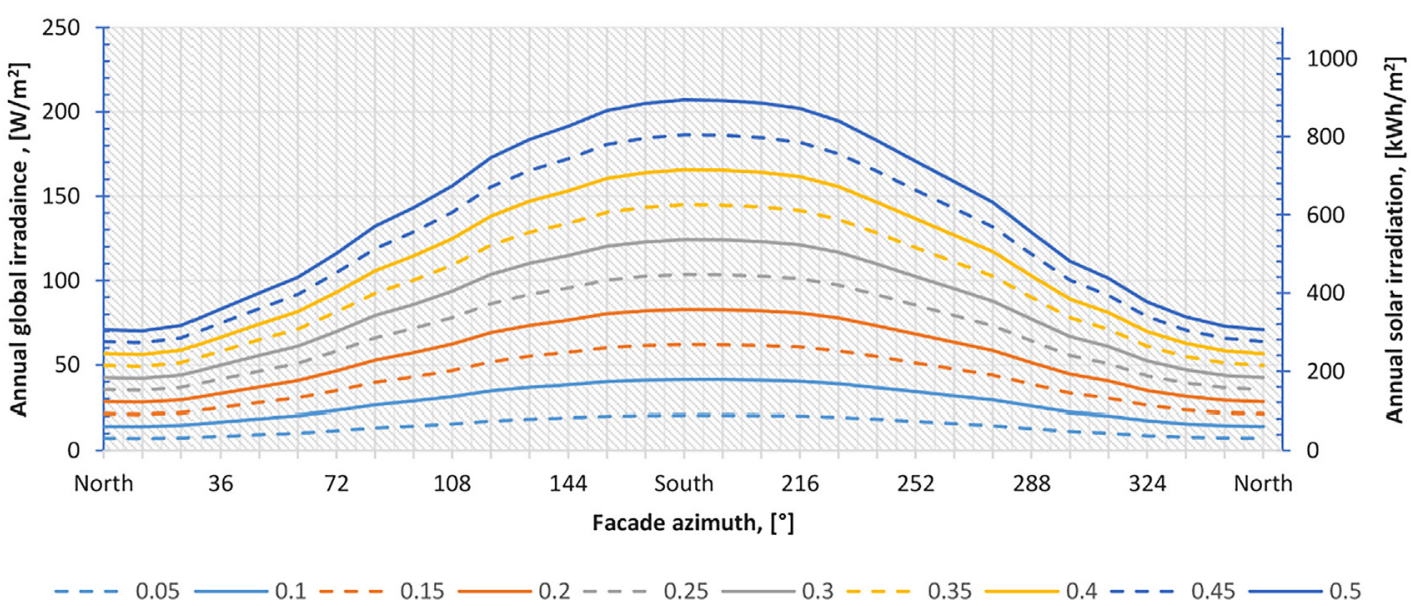

(c)

Fig. 7. Graphical tool for estimating annual global irradiance $\left[\mathrm{W} / \mathrm{m}^{2}\right]$ (left vertical axis), and annual global irradiation $\left[\mathrm{kWh} / \mathrm{m}^{2}\right]$ (right vertical axis) of a vertical façade, as a function of its azimuth degree (horizontal axis) and average SVF (curves), in Athens (a), London (b) and Helsinki (c).

\section{Conclusions}

Evaluating the solar energy potential of façades using their SVF values would be of great relevance to professionals working in the field of urban environmental design. SVF is a geometric measure, independent of latitude and location, and its calculation is faster and less complicated compared to solar simulations. Using the annual climatic data of three cities, Athens, London, and Helsinki, the study demonstrated that the relationship between SVF and annual global irradiance on vertical façades is linear and very strong, with the $\mathrm{R}^{2}$ being above 0.8 in all 30 façade orientations, independently of location. Thus, it is argued that the SVF is a good predictor of façades' annual global 


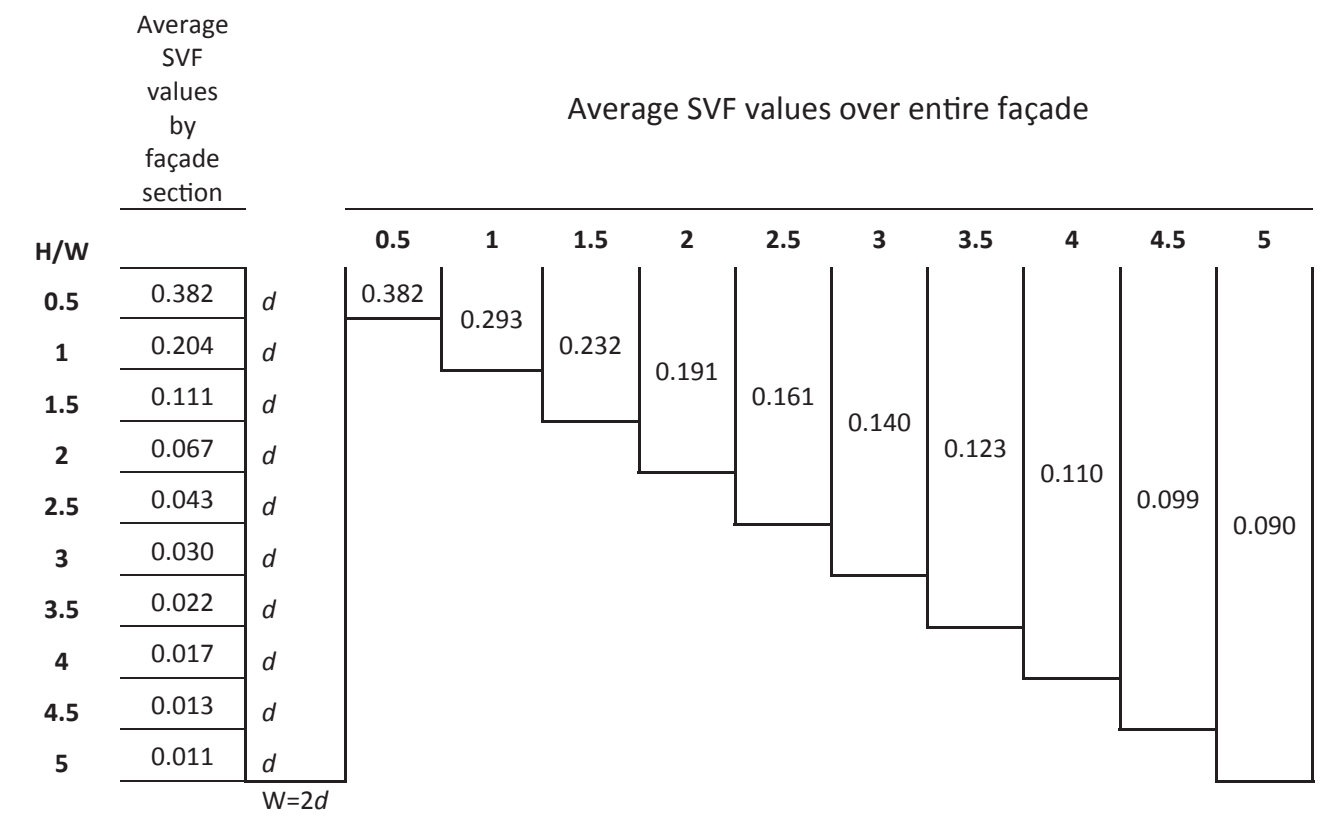

Fig. 8. Average façade SVF values for an urban canyon of varying H/W ratio, referring to the entire façade height, and by façade sections, of height (d) equal to half the canyon's width $(\mathrm{W})$.

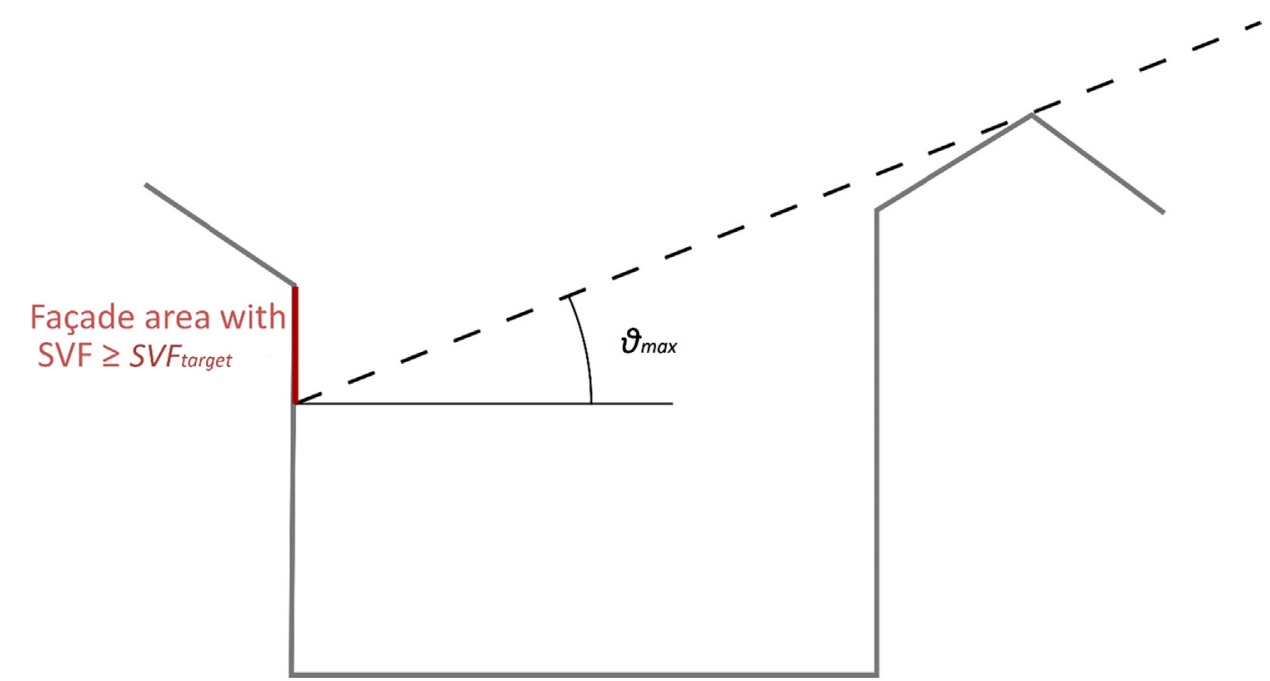

Fig. 9. Section view of an urban canyon with the maximum obstruction angle $\theta_{\max }$ ensuring that the highlighted upper section of the façade has SVF values exceeding a specified $S V F_{\text {target }}$ value.

irradiation, and can be used as such, at least for locations within the range of the tested latitudes, i.e. from about $38^{\circ}$ to $60^{\circ}$. Additionally, since both dominant components of solar irradiation correlate equally well with the SVF, namely sky diffuse radiation and direct radiation for orientations facing the annual sun path, it is assumed that the climate of the location does not affect its prediction capability significantly.

To exemplify the significance and usability of the research, the models obtained from the linear regression analysis for each city - 30 linear functions, one by orientation - are integrated into graphical tools for predicting annual global irradiation of a façade surface, based on its average SVF and azimuth. The graphs are intended for architects practicing in Athens, London and Helsinki, for evaluating the PV solar energy potential in existing and new building façades, and/or identifying suitable façades for the application of solar active strategies, at the early design stages. Presumably, similar graphs can be produced for any location within the tested latitude range, based on its annual climatic data.

Furthermore, the study contributes to understanding the factors affecting the relation between SVF and solar availability on vertical façades by repeating the analysis for two months, January and July. The results demonstrated that the capability of the SVF to predict monthly global irradiance is relatively limited and varies significantly among different locations. This behaviour is attributed to the increased effect of the solar altitude on the relationship of the SVF with monthly direct irradiance. At lower average solar altitudes, such as in January, the strength of the relationship increases with increasing solar altitude. By contrast, at higher average solar altitudes, such as in July, the relationship gets stronger with decreasing solar altitude. The above imply the existence of a critical solar altitude for which the capability of the SVF to predict direct solar irradiances on façades is maximized.

\section{Acknowledgements}

This study has been initially funded by a scholarship from the Kent School of Architecture, University of Kent. It was later continued at the Smart Living Lab (http://www.smartlivinglab.ch) as part of the 
ATHENS

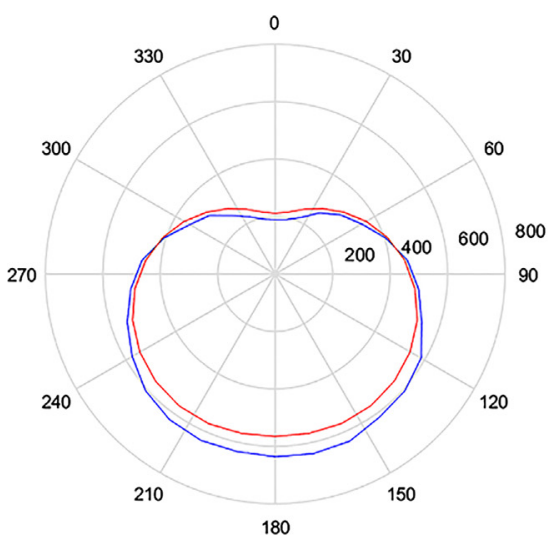

180
LONDON

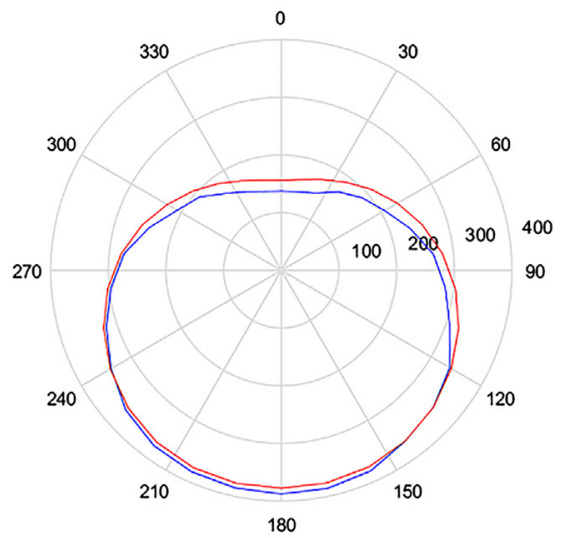

HELSINKI

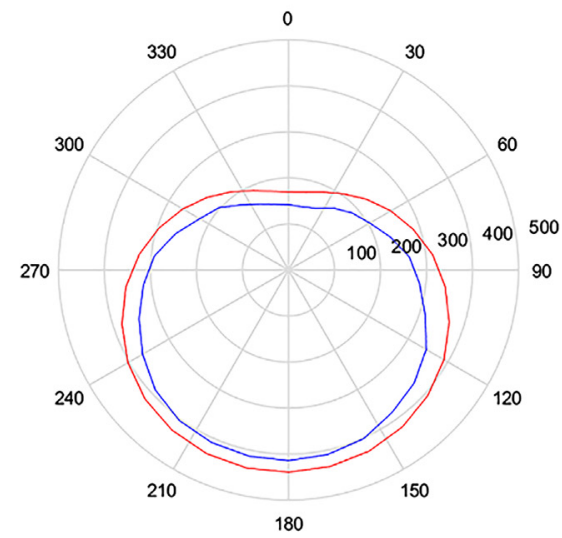

\section{Simulations \\ METEONORM}

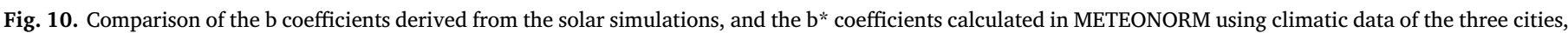
for 30 directions. (For interpretation of the references to colour in this figure legend, the reader is referred to the web version of this article.)

research project INDALUX funded by the Haute Ecole d'ingénierie et d'architecture de Fribourg (HEIA-FR) and a grant from the ARUP company.

\section{References}

Assouline, D., Mohajeri, N., Scartezzini, J.-L., 2017. Quantifying rooftop photovoltaic solar energy potential: a machine learning approach. Sol. Energy 141, 278-296.

Bergamasco, L., Asinari, P., 2011. Scalable methodology for the photovoltaic solar energy potential assessment based on available roof surface area: application to Piedmont Region (Italy). Sol. Energy 85, 1041-1055.

Biyik, E., Araz, M., Hepbasli, A., Shahrestani, M., Yao, R., Shao, L., Essah, E., Oliveira, A.C., et al., 2017. A key review of building integrated photovoltaic (BIPV) systems. Eng. Sci. Technol. Int. J. 20, 833-858.

Brito, M.C., Freitas, S., Guimarães, S., Catita, C., Redweik, P., 2017. The importance of facades for the solar PV potential of a Mediterranean city using LiDAR data. Renew. Energy 111, 85-94.

Chatzipoulka, C., Compagnon, R., Nikolopoulou, M., 2016. Urban geometry and solar availability on façades and ground of real urban forms: using London as case study. Sol. Energy 138, 53-66.

Chatzipoulka, C., Nikolopoulou, M., 2018. Urban geometry, SVF and insolation open spaces: London and Paris. Build. Res. Inf. http://dx.doi.org/10.1080/09613218. 2018.1463015 .

Cheng, V., Steemers, K., Montavon, M., Compagnon, R., 2006. Compact cities in a sustainable manner. 2nd International Solar Cities Congress. Oxford, UK, 3-6 April 2006.

Compagnon, R., 2004. Solar and daylight availability in the urban fabric. Energy Build $36,321-328$.

Cronemberger, J., Caamaño-Martín, E., Sánchez, S.V., 2012. Assessing the solar irradiation potential for solar photovoltaic applications in buildings at low latitudes making the case for Brazil. Energy Build. 55, 264-272.

Eliasson, I., 1996. Urban nocturnal temperatures, street geometry and land use. Atmosph. Environ. 30, 179-192.

EPBD, 2010. Directive 2010/31/EU of the European Parliament and of the Council of 19 May 2010 on the energy performance of buildings. Off. J. Eur. Union 13-35.

Esclapés, J., Ferreiro, I., Piera, J., Teller, J., 2014. A method to evaluate the adaptability of photovoltaic energy on urban façades. Sol. Energy 105, 4141-4427.

Evola, G., Margani, G., 2016. Renovation of apartment blocks with BIPV: energy and economic evaluation in temperate climate. Energy Build. 130, 794-810.

Giridharan, R., Lau, S.S.Y., Ganesan, S., Givoni, B., 2007. Urban design factors influencing heat island intensity in high-rise high-density environments of Hong Kong. Build. Environ. 42, 3669-3684.

Hachem, C., Athienitis, A., Fazio, P., 2012. Design of roofs for increased solar potential BIPV/T systems and their applications to housing units. ASHRAE Trans. 118, 660-676.

Hachem, C., Athienitis, A., Fazio, P., 2014. Energy performance enhancement in multistory residential buildings. Appl. Energy 116, 9-19.

International Energy Agency, 2014. World Energy Outlook. OECD Publishing, Paris.

Jelle, B.P., Breivik, C., Røkenes, H.D., 2012. Building integrated photovoltaic products: a state-of-the-art review and future research opportunities. Solar Energy Mater. Solar Cells 100, 69-96.
Jelle, B.P., 2015. Building integrated photovoltaics: a concise description of the current state of the art and possible research pathways. Energies 9, 21.

Kanters, J., Horvat, M., 2012. Solar energy as a design parameter in urban planning. Energy Proc. 30, 1143-1152.

Karteris, M., Theodoridou, I., Mallinis, G., Papadopoulos, A., 2014. Façade photovoltaic systems on multifamily buildings: an urban scale evaluation analysis using geographical information systems. Renew. Sustain. Energy Rev. 39, 912-933.

Lobaccaro, G., Carlucci, S., Croce, S., Parapella, R., Finocchiaro, L., 2017. Boosting solar accessibility and potential of urban districts in the Nordic climate: a case study in Trondheim. Sol. Energy 149, 347-369.

Mavromatidis, G., Orehounig, K., Carmeliet, J., 2015. Evaluation of photovoltaic integration in a village. Sol. Energy 121, 152-168.

Mohajeri, N., Upadhyay, G., Gudmundsson, A., Assouline, D., Kämpf, J., Scartezzini, J.-L., 2016. Effects of urban compactness on solar energy potential. Renew. Energy 93, 469-482.

Montavon, M., Scartezzini, J.-L., Compagnon, R., 2004. Comparison of the solar energy utilisation potential of different urban environments. In: PLEA2004 - 21st International Conference on Passive and Low Energy Architecture. Eindhoven, The Netherlands, 19-22 September 2004.

Mulcué-Nieto, L.F., Mora-López, L., 2014. A new model to predict the energy generated by a photovoltaic system connected to the grid in low latitude countries. Sol. energy 107, 423-442.

Mulcué-Nieto, L.F., Mora-López, L., 2015. Methodology to establish the permitted maximum losses due to shading and orientation in photovoltaic applications in buildings. Appl. Energy 137, 37-45.

Norton, B., Eames, P., Mallick, T., Huang, M.J., McCormack, S., Mondol, J., Yohanis, Y., 2011. Enhancing the performance of building integrated photovoltaics. Sol. Energy $85,1629-1664$.

Paatero, J.V., Lund, P., 2006. Effects of large-scale photovoltaic power integration on electricity distribution networks. Renew. Energy 32, 216-234.

Pearce, J.M., 2002. Photovoltaics - a path to sustainable futures. Futures 34, 663-674.

Peng, C., Huang, Y., Wu, Z., 2011. Building-integrated photovoltaics (BIPV) in architectural design in China. Energy Build. 43, 3592-3598.

Project PREcis, 2000. PREcis: Assessing the Potential for Renewable Energy in Cities. Final report, Project no. JOR3-CT97-0192, 2000.

Ratti, C., Raydan, D., Steemers, K., 2003. Building form and environmental performance: archetypes, analysis and an arid climate. Energy Build. 35, 49-59.

Redweik, P., Catita, C., Brito, M., 2013. Solar energy potential on roofs and facades in an urban landscape. Sol. Energy 97, 332-341.

Remund, J., Müller, S., Kunz, S., Huguenin-Landl, B., Studer, C., Klauser, D., Schilter, C., Lehnherr, R., 2015. METEONORM - Global Meteorological Database, Handbook Part I \& II, Version 7. Meteotest \& Swiss Federal Office for Energy, Bern.

Robinson, D., 2006. Urban morphology and indicators of radiation availability. Sol. Energy 80, 1643-1648.

Sánchez, E., Izard, J., 2015. Performance of photovoltaics in non-optimal orientations: an experimental study. Energy Build. 87, 211-219.

Steyn, D.G., 1980. The calculation of view factors from fisheye-lens photographs. Atmosph. Ocean 18, 254-258.

Šúri, M., Huld, T.A., Dunlop, E.D., Ossenbrink, H.A., 2007. Potential of solar electricity generation in the European Union member states and candidate countries. Sol. Energy 81, 1295-1305.

Ward Larson, G., Shakespeare, R., 1998. Rendering with Radiance: The Art and Science of Lighting Visualisation. Morgan Haufmann, San Francisco. 
Wall, M., Munari Probst, M.C., Roecker, C., Dubois, M.-C., Horvat, M., Jørgensen, O.B., Kappel, K., 2012. Achieving solar energy in architecture - IEA SHC Task 41. Energy Proc. 30, 1250-1260.

Wiginton, L.K., Nguyen, H.T., Pearce, J.M., 2010. Quantifying rooftop solar photovoltaic potential for regional energy policy. Comput. Environ. Urban Syst. 34, 345-357.

Wittmann, H., Bajons, P., Doneus, M., Friesinger, H., 1997. Identification of roof areas suited for solar energy conversion systems. Renew. Energy 11, 25-36.

Yun, G.Y., Steemers, K., 2009. Implications of urban settings for the design of photovoltaic and conventional façades. Sol. Energy 83, 69-80.

Zanchetta, E., 2017. Potentiel photovoltaïque en façade. Technical report: LESO-PB/ EPFL, Lausanne.

Zhang, J., Heng, C.K., Malone-Lee, L.C., Hii, D.J.C., Janssen, P., Leung, K.S., Tan, B.K., 2012. Evaluating environmental implications of density: a comparative case study on the relationship between density, urban block typology and sky exposure. Automat. Constr. 22, 90-101. 